Military Technical College

Kobry El-Kobbah, Cairo, Egypt.

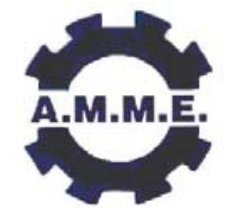

$13^{\text {th }}$ International Conference on Applied Mechanics and Mechanical Engineering.

\title{
FABRICATION OF MAGNESIUM ALLOY FROM A PRE-ALLOYED POWDER USING HOT DIE COMPACTION PROCESS
}

\author{
ZULKOFFLI* Z., DAUD* M.A.M., SYARIF** J. and SAJURI** Z.
}

\begin{abstract}
AZ91D magnesium alloy was fabricated by using pre-alloyed powder compressed without any binder agent at $280^{\circ} \mathrm{C}$ under the compaction pressure of $200 \mathrm{MPa}$ at different time intervals of 2, 4, 6, 8 and 10 hours. Some of the compressed samples were then undergone a sintering process at temperature of $450^{\circ} \mathrm{C}$ for 3 and 6 hours. Furnace cooling was performed after the sintering. Microstructure and hardness of each specimen were investigated. The microstructures observation and hardness investigation of the as-hot compacted and sintered samples were then compared. The results showed that microstructure transformation occurred due to the hot compaction and the sintering for 3 and 6 hours. The as-hot compacted samples showed a grown globular precipitates ( $\beta$ phase, $\mathrm{Mg}_{17} \mathrm{Al}_{12}$ ) distributed uniformly in grains. However, after sintering process, lamellar precipitates took place and dominated the grains. The as-hot compacted sample showed higher hardness value compared to the 3 hours and 6 hours sintered samples.
\end{abstract}

\section{KEY WORDS}

Powder compaction, high temperature, sintering, precipitation, magnesium alloy

* Graduate student, Dept of Mechanical and Materials Engineering, National University of Malaysia.

** Lecturer, Dept of Mechanical and Materials Engineering, National University of Malaysia 


\section{INTRODUCTION}

Magnesium alloys have a great potential to be applied in automotive and aerospace industries due to their promising advanced properties such as high specific strength and modulus, besides its lightweight compared to other structural materials such as aluminium and titanium alloys.

Over the past 15 years, the average mass of car has increased about $15-20 \%$ per vehicle and this resulted in an increase in the fuel consumption ranging from 6 to $10 \%$ in order to maintain comparable car performance. The increase in fuel consumption will directly contribute to the increases in emission of amount of greenhouse gases such as $\mathrm{CO}, \mathrm{CO}_{2}$, etc. Kyoto protocol required developed and developing nations to reduce greenhouse gas emission, as they are the major contributor to global warming. As $\mathrm{CO}$ and $\mathrm{CO}_{2}$ emissions are in direct proportion to fuel consumption, cars weight has become one of the most critical criteria of design efficiency assessment. Recently, engineers in most leading automakers are concentrating their efforts on the reduction of weight of car in order to increase the performance and efficiency of the vehicle. This can be done by designing new concept of environmental friendly vehicle or introducing new light materials. Magnesium and its alloys are their right choice. Magnesium has the lowest density (about $1.74 \mathrm{~g} / \mathrm{cm}^{3}$ ) among the engineering structural materials. According to Mordike et al. [1] and Duffy [2] magnesium alloys exhibited the best performance as a light alloy in automotive and aerospace application. Because of that the demand of magnesium alloys from many automakers has considerably increased in the recent decade. Cole et al. [3] reported that magnesium alloys become demanding because of the growing trend to substitute $\mathrm{Al}$ and $\mathrm{Mg}$ for conventional steel and cast irons in vehicles due to fuel economy and to reduce emissions.

Several methods have been used to fabricate magnesium alloys including sand casting [4], gravity die casting [5], high pressure squeeze casting [6], pressure die casting [7], powder metallurgy $[8,9]$ etc. Among the processes investigated, powder metallurgy has a number of advantages, i.e. powder metallurgy parts can be mass-produced to net shape or near net shape by eliminating or reducing the need for subsequent machining. This process also wastes very little material, where almost $97 \%$ of starting powders are converted to product and can be made with a specified level of porosity to produce porous metal parts. Conventional powder metallurgy method involved the processes of blending and mixing of powder, compacting or pressing the powder into desired shape and followed by sintering. A molten polymer (called binder) usually used in compounding the metal powders. To remove the binder an extra process, i.e. de-binding process has to be introduced before the sintering. The density and strength of the material before sintering process are low. Sintering increases both properties of material. In sintering process, temperature and time are very important parameters to initiate the solid-state bonding (fusion) of particles and strengthening of materials. 
In this study, the microstructures and hardness of AZ91D magnesium alloy fabricated using powder compaction method at high temperature was investigated. The pre-alloyed powder of AZ91D magnesium alloy was compacted at $280^{\circ} \mathrm{C}$ before sintered at temperature of $450^{\circ} \mathrm{C}$ for 3 and 6 hours. Through the above process, it is possible to eliminate the binding and de-binding process that are usually practiced in powder metallurgy process.

\section{MATERIALS AND EXPERIMENTAL PROCEDURE}

The chemical composition of AZ91D magnesium alloy powder used is shown in Table 1. The major alloying elements of AZ91D magnesium alloy are aluminium (9 wt. \%) and zinc (1 wt. \%). The average particle size of magnesium alloy powder was $150 \mu \mathrm{m}$. In order to perform compaction of pre-alloyed powder, a die was specially designed and fabricated. The diameter of the die cavity is $25 \mathrm{~mm}$.

To fabricate the sample, 5 grams of pre-alloyed AZ91D powder were filled in the die cavity and puncher was slightly pressed into the die. Before the compaction process proceeded, the die was pre-heated with gentle load applied on the die for 30 minutes at temperature of $280^{\circ} \mathrm{C}$. The samples were then compressed under the pressure of 200 $\mathrm{MPa}$ using a 50 tones capacity hot press machine at different time intervals, i.e. 2, 4, 6, 8 and 10 hours at $280^{\circ} \mathrm{C}$. The process flow of the samples fabrication is shown in Fig. 1. The size of the as-hot compacted sample was $25 \mathrm{~mm}$ and $4 \mathrm{~mm}$ in diameter and height, respectively, as shown in Fig. 2. To initiate a solid-state bonding of particles, some of samples were then sintered in a furnace at a temperature of $450^{\circ} \mathrm{C}$ for 3 and 6 hours. The sintering was followed by furnace cooling until the samples reached the surrounding temperature. To get the microstructure, the samples were polished with \#200 to \#1500 grit emery papers. To obtain a mirror-like surface, diamond paste of $1 \mu \mathrm{m}$ size was used together with micro-cloth in the final stage of polishing. After polishing, the samples were etched to get the microstructure. The etching solution used was $6 \mathrm{~g}$ picric acid, 100 $\mathrm{ml}$ ethanol and $10 \mathrm{ml}$ acetic acid. The microstructure was then observed under an optical microscope.

Vickers Hardness Tester was used to evaluate the hardness of the as hot-compacted and sintered samples. The load applied and the duration of indentation was $1000 \mathrm{~g}$ and 20 second, respectively. At least 10 data of hardness from each sample was taken and the average of hardness is calculated. To get the hardness of secondary phases, the load applied and the duration of indentation was $50 \mathrm{~g}$ and 10 seconds, respectively. 


\section{RESULTS AND DISCUSSION}

\section{Microstructure}

Before detail investigations and experiments conducted, the particle microstructure of the as received pre-alloyed AZ91D powder was investigated. The optical microscope observation results on the particle shape and microstructure of as-received material is shown in Fig. 3(a). The as-received powder particles were mostly in equiaxed shape. Figure 3(b) shows the particle arrangement after hot compaction process for 6 hours at $200 \mathrm{MPa}$ at $280^{\circ} \mathrm{C}$. It is found that at higher magnification, numbers of tiny globular precipitates distributed in the particle as shown in Fig. 3(c). Further, a small amount of lamellar precipitation nucleated in some area along the particle boundary as shown in Fig. 3(d). These precipitations are believed to be an intermetallic compound of aluminium and magnesium known as $\mathrm{Mg}_{17} \mathrm{Al}_{12}$, which nucleated during the cooling process after casting. According to Zhifeng Li et al. [10] and Zheng et al. [11] magnesium alloy cast ingot usually contains large amounts of $\mathrm{Mg}_{17} \mathrm{Al}_{12}$ divorced distrusting along the grain boundary. However before hot deformation, these compounds are usually arterially resolved into matrix after heat treatment.

The microstructure observation results of as-hot compacted, 3 hours and 6 hours sintered samples are shown in Fig. 4. From the figure, it can be seen that the average particles size for all samples was about $150 \mu \mathrm{m}$. After etching, the boundary of inter-particles appeared clearer compared to the grain boundaries. The grain boundaries of the material itself could be observed within the particle and can be seen clearly in the sample without sintering. The average grain size was about $15 \mu \mathrm{m} \sim 20 \mu \mathrm{m}$.

There are two distinct phases observed in the microstructure; primary $\alpha$ phase (magnesium solid solution), which relatively bright in color and $\beta$ phase $\left(\mathrm{Mg}_{17} \mathrm{Al}_{12}\right)$ along grain boundaries and in globular or lamellar structures, which appeared slightly in darker domains. For the as-hot compacted sample, some amount of globular precipitates took place along the particle boundary as shown in Fig. 4(a). The size of precipitates was larger compared to the size of fine globular precipitates observed in the as-received powder particles. However, the lamellar precipitates, which was not observe in samples without sintering, was identified in large amount in samples sintered at $450^{\circ} \mathrm{C}$ for 3 and 6 hours as shown in Fig. 4(b) and (c). Further, the precipitates in 6 hours sintered sample transformed into coarse globular and gathered around compared to that in 3 hours sintered sample which was finer and uniformly distributed. The size of globular and lamellar precipitates in the as-hot compacted sample, and samples sintered for 3 and 6 hours were larger compared to that of the precipitates observed in the as-received powder particle. This is because the precipitation grew during the process of slow cooling after compaction and sintering at $280^{\circ} \mathrm{C}$ and $450^{\circ} \mathrm{C}$, respectively.

The as-hot compacted sample was gone through a process of compaction under 
pressure of $200 \mathrm{MPa}$ at temperature of $280^{\circ} \mathrm{C}$. Under this condition, the material already entered the magnesium solid solution ( $\alpha$ ) zone slightly above solubility line according to the Mg-Al phase diagram. During the cooling process, the temperature decrease below the solubility line and nucleate precipitation of $\beta$ intermetallic compound $\left(\mathrm{Mg}_{17} \mathrm{Al}_{12}\right)$. The precipitates were found in globular shape. To initiate the globular shape precipitation, it needs very high energy. Hamana et al. [12] reported in their research that, in the ageing process of Al-Mg alloy the formation of the precipitation particles in the shape of fine globules at the beginning and transform of these globular into lamellar shape. However, the temperature introduced in the compaction process was not high enough to provide energy to produce a globular shape precipitation. Therefore, it is assumed that the energy to produce the globular shape precipitation was generated from the high compaction pressure. This high compaction pressure (200MPa) is above the yield strength of the material at room temperature. It is known that the yield strength for die cast AZ91D magnesium alloy at room temperature was 160MPa. [13]. Therefore, at the present pressure and temperature, significant dislocations could occur. The globular $\beta$ phase is believed tends to precipitates at these dislocation points. The accumulation of dislocations during the compression of globular $\beta$ phase at the dislocation sites may contribute to higher strength of the material. These globular $\beta$ precipitations and the dislocations may contribute to higher strength of the material.

For samples sintered for 3 and 6 hours at $450^{\circ} \mathrm{C}$, lamellar precipitates mainly observed in both samples. At $450^{\circ} \mathrm{C}$ sintering condition, the samples heated to solid solution temperature, which allowed the occurrence of recovery of crystal defects (dislocations) and released of the internal stresses that caused by the high external pressure applied on the samples. This resulted in softening of the material. During the cooling process, as temperature of the material decreased below the solubility temperature, precipitation of second phase $(\beta)$ occurred. The precipitation can be easily observed along the grain boundaries and it grows into grain, when the material was slowly cooled down. The volume fraction of the precipitates is depending on the percentage of impurity (alloying element such as aluminium) and the cooling time. Detailed analysis on microstructures showed that the volume fraction of precipitates in 3 and 6 hours sintered samples are almost the same. However, the lamellar precipitates in 6 hours sintered sample was thicker compared to that in 3 hours sintered sample as shown in Fig. 4(c). This clearly illustrates that the precipitation grows in size as time increases. It is believed that the lamellar precipitates grow along the basal plane (0001) of magnesium hexagonal close-packed structure as reported by Yoo et al. [14]. The report says that precipitation of second phase grew along the basal plane of hcp metals.

\section{Hardness}

Figure 5 shows the hardness comparison of as-hot compacted, 3 and 6 hours sintered samples. The result showed that as-hot compacted sample exhibited highest average hardness compared to that of sintered samples. The highest hardness obtained was 
$88 \mathrm{Hv}$ for samples compacted for 4 and 8 hours at $280^{\circ} \mathrm{C}$. For sintered samples, in overall, longer sintering time gives higher average hardness compared to shorter sintering time. The hardness for sintered samples showed the tendency to increase with compaction time. The highest hardness obtained for 3 and 6 hours sintered samples were $82 \mathrm{Hv}$ and $84 \mathrm{Hv}$, respectively.

To understand the differences in hardness and the strengthening mechanisms involved in all three different processes used in this study, the hardness test results was analyze in parallel with the microstructures. And detail hardness measurement on the different phases i.e. $\alpha(\mathrm{mg})$ phase, globular and lamellar structure of $\beta\left(\mathrm{Mg}_{17} \mathrm{Al}_{12}\right)$ phase in various stages of each process was conducted.

It was found that the higher hardness obtained in sample without sintering was due to the presence of tiny globular precipitates that widely distributed in the matrix. Globular precipitation is known as the effective strengthening mechanism for alloy materials. The tiny globular precipitates could be observed at higher magnification through an optical microscope as shown in Fig. 4(a). The size of the globular precipitates increased with the increasing of compaction time. However, because the volume fraction of globular $\beta$ phase does not change, the growth of the size of globular precipitates was actually due to the merging of several tiny precipitates. Because of this, the distance between one precipitates to another increased and results in decrease of hardness of the matrix. In addition, the increased in hardness may be also due to the accumulation of dislocations that caused by high compaction pressure above the yield strength of the material at high temperature $\left(280^{\circ} \mathrm{C}\right)$.

The hardness results for as-hot compacted and sintered samples demonstrated that a good enough sample with reliable hardness could be obtained by hot compaction process at temperature of $280^{\circ} \mathrm{C}$ compressed at $200 \mathrm{MPa}$. Meaning that the sintering process on the compacted sample could also be eliminated. However, it is suggested that the temperature for hot compaction may be increased close to sintering temperature to obtain compacted product with better mechanical properties.

\section{CONCLUSION}

AZ91D magnesium alloy was fabricated from a pre-alloyed powder using a hot compaction technique at temperature of $280^{\circ} \mathrm{C}$ at several compaction times. The microstructures and hardness of the as-hot compacted and sintered samples were investigated. The findings are concluded as follows:

1. The as-hot compacted sample shows higher hardness compared to sintered samples. The sintering process allows some recovery of defects and releasing internal stresses and leads to the softening of material.

2. Globular and lamellar precipitation hardening play an important role as the 
strengthening mechanism in hot compacted AZ91D magnesium alloy.

3. AZ91D magnesium alloy can be produced by hot compaction technique even by eliminating the process of binding and de-binding in conventional powder metallurgy.

\section{REFERENCES}

[1] Mordike, B.L., Ebert, T., "Magnesium: Properties-Application-Potential”, J. Mater. Sci. Engng, A302, pp37-45. (2001).

[2] Duffy, L., "Magnesium Alloys: The Light Choice for Aerospace", Materials World, pp.127-130, (1996).

[3] Cole, G.S.. Sherman, A.M., "Lightweight Materials for Automotive Applications, Materials Characterizations", No. 35, pp3-9. (1995).

[4] John F.K., Gordon A.F., "A High Strength, Corrosion Resistant Magnesium Alloy for Aerospace Casting", Light Weight Alloys for Aerospace Application II, pp. 423-438, (1991).

[5] Aghion, E., Bronfin, B., Eliezer, D., Von Buch, F., Schumann, S. and Friedrich, H., "The art of Developing New Magnesium Alloys for High Temperature Application", Mater. Sci. Forum Vol.419-422 (2003) p.407.

[6] Ming Zhou, Henry Hu, Naiyi Li and Jason Lo, "Microstructure and Tensile Properties of Squeeze Cast Magnesium Alloy AM50", J. of Materials Engineering and Performance. Vol.14(4), pp539-545, (2005).

[7] Gokan, Y., Suzuki, A., Nozawa, S., Anyanwu, I.A., Kamado, S., Kojima, Y., Takeda, S., and Ishida, T., "Development of Heat Resistant Mg-Zn-Al-Ca-RE Diecasting Alloys", Mater. Sci. Forum Vol.419-422 (2003) p.451.

[8] Wen Xie, Yue Liu, De Song Li, Jian Zhang, "Influence of sintering routes to the mechanical properties of magnesium alloy and its composites produced by PM technique", J. Alloys and Compounds.Vol.431, pp162-166, (2007).

[9] Ding C.H., Yang Z.M., Zhang H.T., "Microstructure and tensile strength of PM304.J of. Composite", Part A 38, pp348-352, (2007).

[10] Zhifeng Li, Jie Dong, Xiao Qing Zeng, Chen Lu, Weng Jiang Ding, "Influence of $\mathrm{Mg}_{17} \mathrm{Al}_{12}$ intermetallic compounds on the hot extruded microstructures and mechanical properties of Mg-9AI-1Zn alloy", J. Materials Science and Engineering A. Vol. 466, pp 134-139, (2007).

[11] Zheng, M. Y., Wu, K., Kamado, S., Kojima, Y., "Aging behavior of squeeze cast SiCw/AZ91 Magnesium Metal Composite”, J. Material Science Engineering. A348, pp67-75, (2003).

[12] Hamana, D., Baziz, L., Bouchear, M., "Kinetics and mechanism of formation and transformation of metastable $\beta^{\prime}$-phase in Al-Mg alloys", Materials Chemistry and Physics, Vol. 84, pp 112-119, (2004).

[13] Zainuddin, S., Umehara, T., Miyashita, Y., and Mutoh, Y., "Fatigue life prediction of magnesium alloys for structural applications", Advanced Engineering Materials. 
Vol. 5-12, pp.910-916, (2003).

[14] Yoo, M. H., Agnew, S.R., Morris, J. R., Ho, K. M., "Non Basal slip systems in HCP metals and alloys: source mechanisms", J. Material Science Engineering. A348, pp 67-75, (2003).

Table 1. Chemical composition of the pre-alloyed AZ91D magnesium alloy (in wt.\%)

\begin{tabular}{lllllllll}
\hline $\mathrm{Al}$ & $\mathrm{Zn}$ & $\mathrm{Mn}$ & $\mathrm{Fe}$ & $\mathrm{Ni}$ & $\mathrm{Cu}$ & $\mathrm{Si}$ & $\mathrm{Be}$ & $\mathrm{Mg}$ \\
8.95 & 0.71 & 0.37 & $<0.01$ & $<0.01$ & $<0.01$ & $<0.02$ & $<0.01$ & Bal. \\
\hline \hline
\end{tabular}

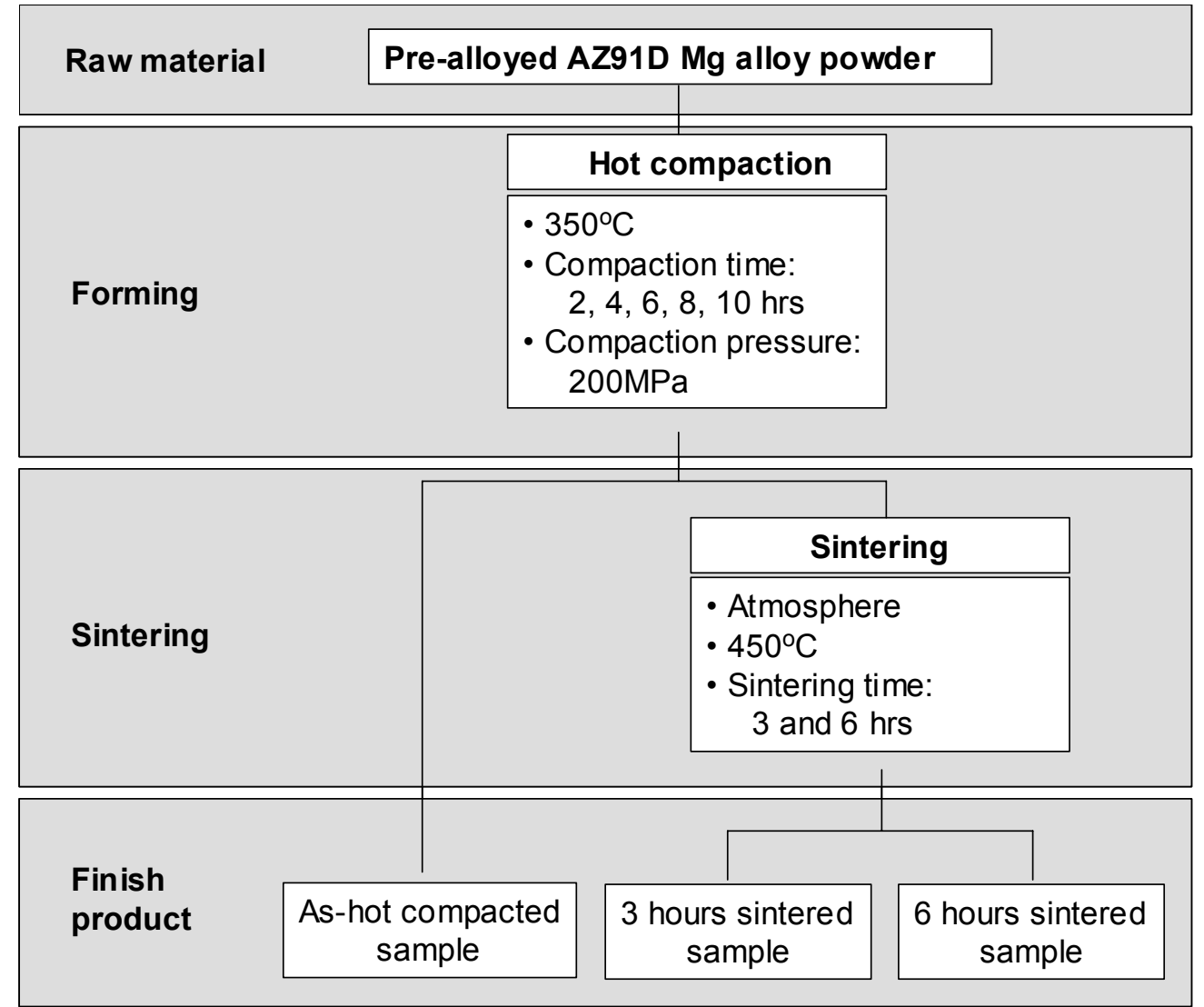

Fig. 1. Process flow of sample fabrication 


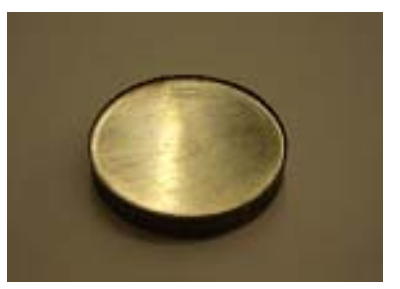

Fig. 2. As-hot compacted sample
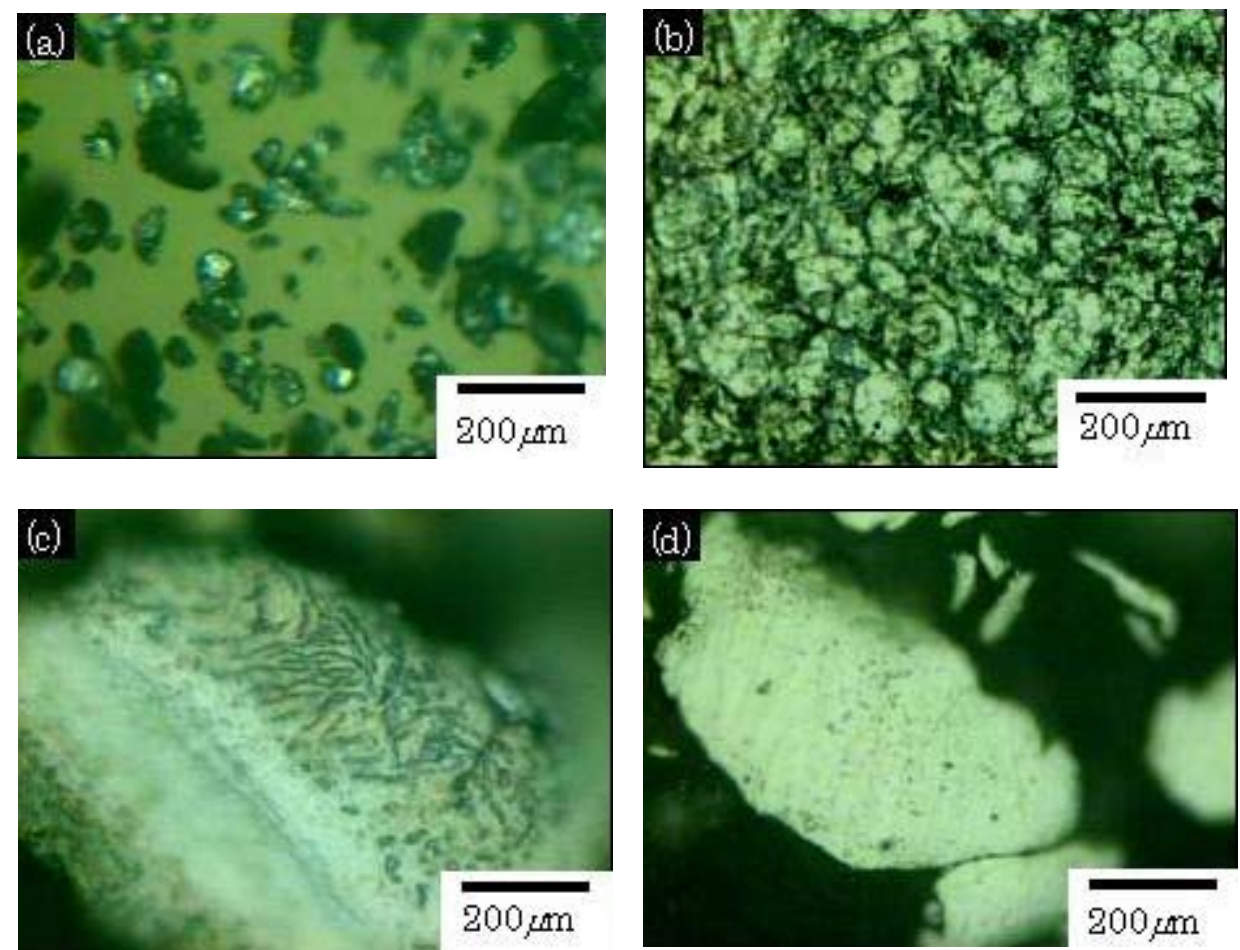

Fig. 3. The powder magnesium alloy AZ91D. (a) As-received material, (b) particle arrangement after hot compaction process for 6 hours at $200 \mathrm{MPa}$ at $350^{\circ} \mathrm{C}$, (c) the lamellar precipitates observed on the as-received material and (d) the microstructure of as received material that contain tiny globular precipitates. 

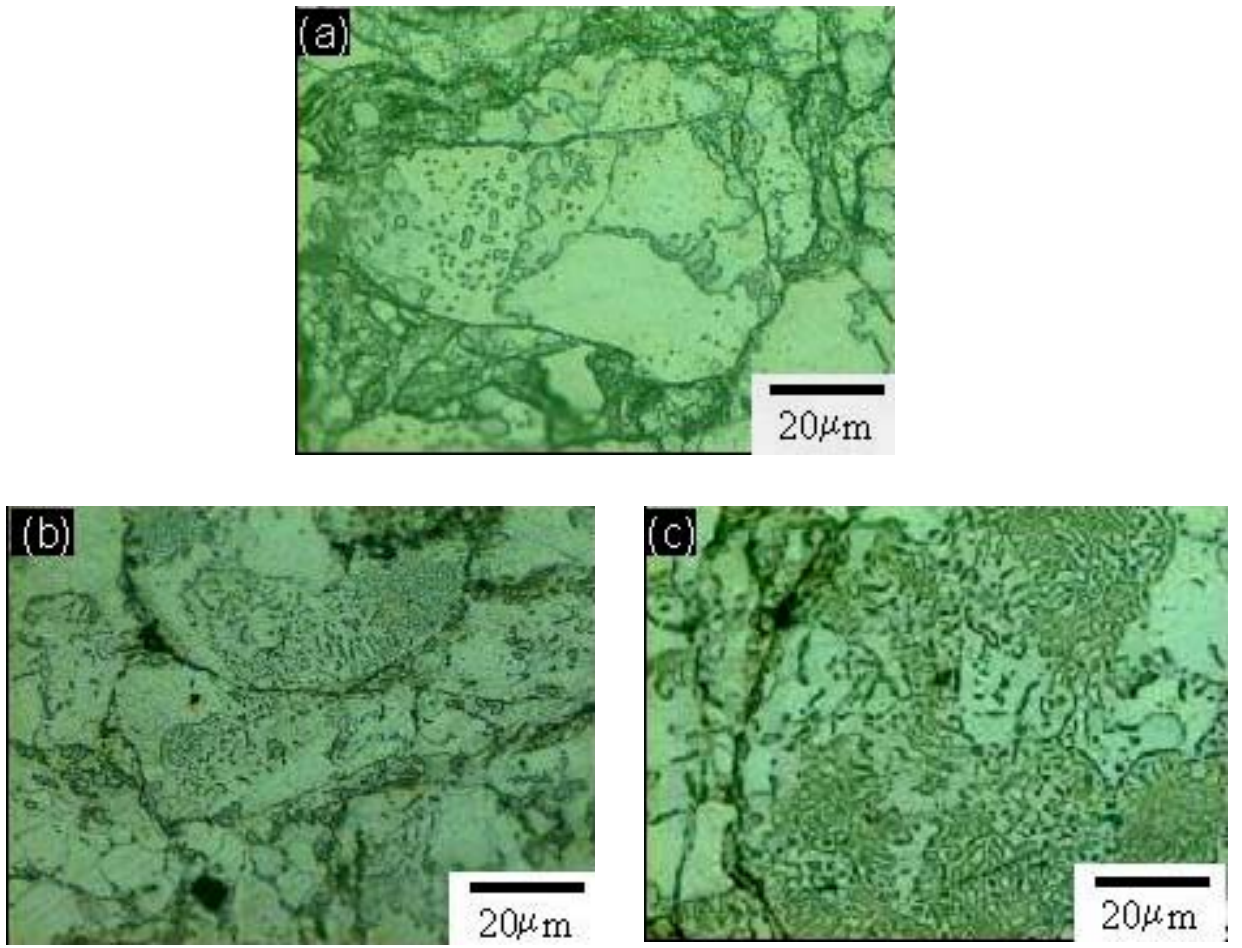

Fig. 4. Optical micrograph showing microstructure of samples (a) as-hot compacted sample (b) 3 hour sintering (c) 6 hour sintering

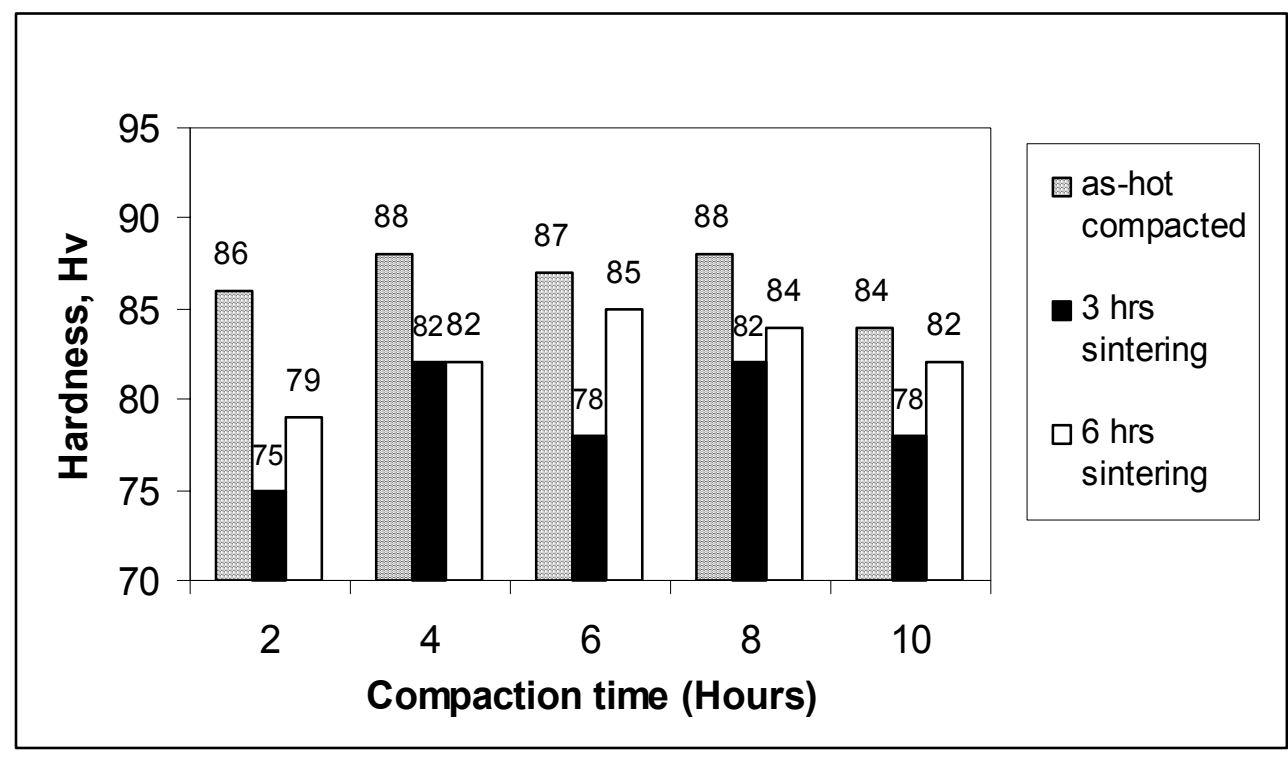

Fig. 5. Hardness of the AZ91D magnesium alloy as-hot compacted, 3 hours and 6 hours sintered samples. 